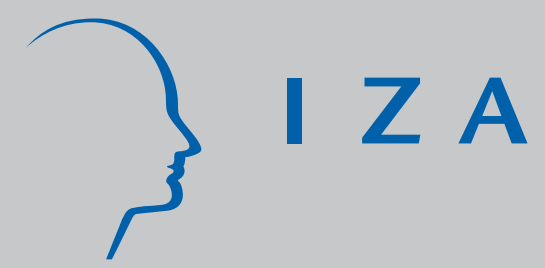

IZA DP No. 8250

Does Foreign Language Proficiency Foster Migration of Young Individuals within the European Union?

Ainhoa Aparicio Fenoll

Zoë Kuehn

June 2014

Forschungsinstitut zur Zukunft der Arbeit Institute for the Study of Labor 


\title{
Does Foreign Language Proficiency Foster Migration of Young Individuals within the European Union?
}

\author{
Ainhoa Aparicio Fenoll \\ Collegio Carlo Alberto \\ and IZA \\ Zoë Kuehn \\ Universidad Autónoma de Madrid \\ Discussion Paper No. 8250 \\ June 2014 \\ IZA \\ P.O. Box 7240 \\ 53072 Bonn \\ Germany \\ Phone: +49-228-3894-0 \\ Fax: +49-228-3894-180 \\ E-mail: iza@iza.org
}

\begin{abstract}
Any opinions expressed here are those of the author(s) and not those of IZA. Research published in this series may include views on policy, but the institute itself takes no institutional policy positions. The IZA research network is committed to the IZA Guiding Principles of Research Integrity.

The Institute for the Study of Labor (IZA) in Bonn is a local and virtual international research center and a place of communication between science, politics and business. IZA is an independent nonprofit organization supported by Deutsche Post Foundation. The center is associated with the University of Bonn and offers a stimulating research environment through its international network, workshops and conferences, data service, project support, research visits and doctoral program. IZA engages in (i) original and internationally competitive research in all fields of labor economics, (ii) development of policy concepts, and (iii) dissemination of research results and concepts to the interested public.
\end{abstract}

IZA Discussion Papers often represent preliminary work and are circulated to encourage discussion. Citation of such a paper should account for its provisional character. A revised version may be available directly from the author. 


\title{
ABSTRACT
}

\section{Does Foreign Language Proficiency Foster Migration of Young Individuals within the European Union?}

\begin{abstract}
Speaking the language of the host country eases migrants' integration and tends to boost their economic success in the country of destination. However, the decision to acquire language skills may in itself be determined by the intention to migrate. In addition, conditional on being a migrant, the relation between language skills and migrants' integration and economic success goes both ways. Using data on the study of foreign languages during compulsory education in European countries, we test whether and how much language proficiency determines migration flows across Europe. The European Union with basically unlimited labor mobility and pronounced differences in youth unemployment rates provides an ideal testing ground for our hypothesis. We find that speaking the language of a country increases the likelihood to migrate to that country almost fivefold.
\end{abstract}

JEL Classification: J61, I20, F22

Keywords: migration, language proficiency, return to skills, education

Corresponding author:

Ainhoa Aparicio Fenoll

Collegio Carlo Alberto

Via Real Collegio 30

Moncalieri (TO) 10024

Italy

E-mail: ainhoa.aparicio@carloalberto.org 


\section{Introduction}

There are huge differences in youth unemployment rates across Europe. In Spain and Greece almost one half of all employable youth are unemployed, followed by Croatia and Portugal where the youth unemployment rate is around 30-35\%. In contrast, the Netherlands has one of the lowest youth unemployment rates in the European Union (EU), with less than $10 \%$ of young individuals without a desired job (see Figure 1.1). Given these pronounced differences in youth unemployment rates and basically unrestricted migration within the EU, one would expect to observe, in particular young individuals, to migrate from countries with high unemployment rates to those with low rates. ${ }^{1}$ Independently of the current situation, young individuals have stronger incentives to migrate because they face lower costs of breaking social ties, and they have a longer working life horizon to recover migration costs. Since the end of the 1990's, there has been a moderate increase in the share of EU foreigners in EU countries, and this increase has been more notable among young individuals (see Figures A-1 and A-2 of the Appendix). However, migration across European countries remains very limited compared to the United States. ${ }^{2}$ According to the OECD [2012b] annual migration rates across EU countries were around $0.3 \%$ in 2010, while US state-to-state migration rates were around $2.4 \%{ }^{3}$

In contrast to the United States, many different national languages are spoken across Europe. ${ }^{4}$ This implies additional migration costs associated with acquiring proficiency in a foreign language. For Europeans, speaking a foreign language thus increases returns to migration, reduces migration costs, and is likely to shape their migration decisions. ${ }^{5}$ The existing literature on the economics of language has mainly focused on two important

\footnotetext{
${ }^{1}$ Prior to 2014, migration and residence was restricted for Bulgarian and Romanian nationals in some EU countries (European Commission [2012]).

${ }^{2}$ One exception is the recent increase in migration from Greece, Portugal, and Spain to Germany, see Figure A-3 of the Appendix.

${ }^{3}$ These numbers are not directly comparable due to differences in distance and population density, but US migration rates are large even compared to within-country migration rates in most European countries: US mobility is about twice as large as mobility in most European countries, with the exception of Scandinavian countries and Great Britain, see Molloy et al [2011]. Even though, or as a consequence of state-to-state migration, differentials in youth unemployment rates across US states tend to be lower. In 2011, unemployment among 16-24 year olds ranged from a low $7.8 \%$ in North Dakota to a high $28.5 \%$ in Rhode Island (Bureau of Labor Statistics [2012]).

${ }^{4}$ The United States do not have any official language at the federal level, but English is the language spoken by most US citizens, and it is official language in 26 US states, see Schildkraut [2001]. According to the US Census [2013], 21\% of individuals aged 5 and over, i.e. 60.6 million, speak a language other than English at home, $62 \%$ of those speak Spanish.

${ }^{5}$ For highly qualified employees of multinational companies the language of the workplace - English might differ from the language of the country of residence, see Chaloff and Lemitre [2009].
} 
Figure 1.1: Youth Unemployment Rates ( $<25$ years) across Europe, 2011

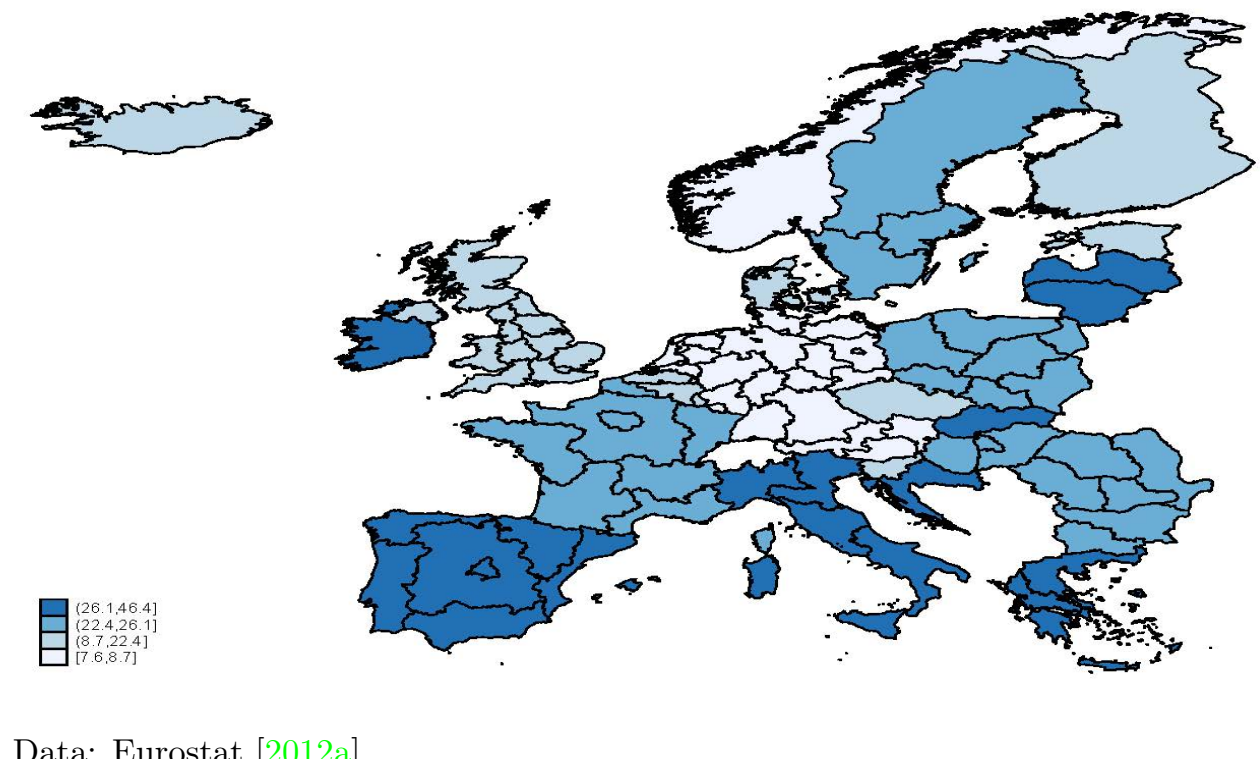

Data: Eurostat [2012a]

aspects of language proficiency: its determinants and its consequences for migrants. Regarding the latter, findings by Bleakley and Chin [2010], Chiswick and Miller [2010], and Dustmann and Fabbri [2003] show that immigrants' accomplishments in a host country's labor market depend positively and to a great extent on their language skills. Regarding the determinants of language proficiency, Chiswick [2008] points out that three aspects: (i) exposure (not being married before migration, not living in an enclave), (ii) efficiency (young age, higher education), and (iii) economic incentives (length of expected stay) positively influence the likelihood that an immigrant acquires proficiency in the host country's language. The current chapter proposes a different perspective that has received little attention: how ex-ante language skills influence individuals' decisions to migrate. Among the few related works are Chiswick and Miller [2001] and Adsera and Pytlikova [2012]. The former show that immigrants from former US, French, or British colonies tend to be more proficient in English or French compared to other immigrants. Adsera and Pytlikova [2012] try to explain migration flows to different OECD countries using linguistic distances to measure the ease of learning a host country's language.

In this chapter, instead of differences in historical ties or measures of linguistic distance we use differences in compulsory learning of foreign languages across Europe and across time as approximations for language skills. We thus add a dynamic dimension to the 
variable "linguistic distance," because learning a foreign language is a way to overcome this distance. This strategy allows us to focus on the effect of language only, and to shut off any confounding effects that hardly vary over time like unobserved or unmeasurable cultural links between countries. In particular, in this chapter we test whether and how much foreign language proficiency directs migration flows of individuals of different age groups within the EU.

Analyzing the effect of foreign language proficiency on migration decisions is not a straight forward task. Simple correlations between measures of proficiency in a language spoken in one country and migration rates to that country are misleading. Studying a foreign language is an individual decision that could primarily be influenced by the individual's desire to move to the particular foreign country. However, according to the Eurobarometer [2012], 68\% of Europeans acquired their language skills at school. For students in most EU countries - with the exception of Ireland - learning a foreign language is not an individual decision, but part of compulsory education. During lower and upper secondary education (ISECD 2 and ISECD 3) students in EU countries study on average 1.5 foreign languages (Eurostat [2012b]). English is taught during compulsory education in 14 of the 27 EU countries. With the exception of Portugal, where fewer than half of all students study English, in all other countries more than $80 \%$ of students study English as a foreign language (see Figure A-4 of the Appendix). In addition, there are also differences across European countries regarding the study of a second foreign language. In most countries, students study French, German, or Spanish as a second compulsory foreign language. Studying German is more common in Central and Eastern Europe, while French tends to be taught in Southern European countries. In many countries, Spanish is the third or fourth most widely taught second foreign language. The same holds true for Italian, but in fewer countries. There are also countries like Germany, Spain, UK, Ireland, and Norway where studying a second foreign language is not part of compulsory education. ${ }^{6}$

Many other factors besides language proficiency determine migration decisions. Economic conditions like unemployment rate, GDP per capita, minimum wage laws, or the generosity of the welfare state also play an important role. To study migration decisions based on countries' relative macroeconomic conditions, the existing literature has typically proposed the use of so-called gravity models; see for instance Ortega and Peri [2009] or Lewer and Van den Berg [2008]. Gravity models explain migration between two countries as a positive function of the "attractive mass" of two economies and a negative function of the distance between them. The "attractive mass" is typically approximated by differences

\footnotetext{
${ }^{6}$ In Germany, learning a second foreign language is only compulsory for students who attend the type of upper secondary education that provides access to universities ("gymnasiale Oberstufe").
} 
in GDP per capita, unemployment rates, population, share of individuals with tertiary education, share of young individuals, and female labor force participation rates. Young individuals are more likely to migrate and hence a larger share of young individuals in the country of origin increases migration. In the destination country, a lower share of young individuals could indicate a generational change and additional job opportunities, thus attracting migration. Higher female labor force participation rates in destination countries are expected to increase migration, especially by women. Furtado and Hock [2010] for the United States and Farré et al [2011] for Spain find that higher female labor force participation rates in destination countries have been made possible - to a certain degree by low skilled migrants covering personal care jobs (e.g. child care and care of the elderly). On the other hand, low female labor force participation rates in countries of origin imply reduced professional options for women, potentially increasing migration. Differences in wages are commonly included in estimations of internal migration decisions - see Kennan and Walker [2011] for the United States. In estimations of cross-country migration, the use of wage differentials has been limited due to problems of data availability; one exception is Bertoli et al. [2013] who consider migration from Ecuador to Spain and to the United States. The distance between two countries, on the other hand, is often measured by the geographic distance, a lack of common borders, lack of a common language, and linguistic distance. In addition, migrant networks have also been found to shape migration decisions. Winters et al [2001] study network effects in the migration from Mexico to the United States. However, traditional gravity models based on differences in geographic and economic conditions cannot account for the magnitude or direction of migration among developed countries. This shortcoming has been pointed out by various studies that have suggested alternative approaches. Belot and Ederveen [2012] propose a model that takes into account both differences in economic variables and religious and cultural distance. ${ }^{7}$ The authors find the latter to explain an important part of migration. They estimate a $1 \%$ higher unemployment rate in the host country to reduce migration by $0.21 \%$, while an increase in cultural or religious distance by $1 \%$ reduces migration by $0.33 \%$ and $0.9 \%$ respectively.

The current chapter proposes the use of a new explanatory variable for migration: the exposure of an individual to compulsory courses in the language of the destination coun-

\footnotetext{
${ }^{7}$ Religious distance is defined by the probability that two random individuals from two countries have a different religion. Cultural distance on the other hand is measured in various ways: Hofstede et al [2010] propose a measure of cultural distance along six dimensions: power distance, uncertainty avoidance, individualism versus collectivism, masculinity versus femininity, pragmatic versus normative, and indulgence versus restraint. The initial measure was based on a survey of IBM employees in 50 different countries. An alternative measure proposed by Inglehart and Baker [2000] relies on answers to the World Value Survey along the two dimensions of: traditional versus secular-rational and survival versus self-expression values.
} 
try. Our empirical strategy compares migration decisions of: (i) individuals of different cohorts from the same country who were exposed or who were not exposed to foreign language courses due to educational reforms, (ii) individuals from different countries but of the same cohort who were exposed or who were not exposed to foreign language courses because of differences in legislation in the two countries. In our estimation we control for economic variables in the countries of origin and destination, as well as for the presence of other co-nationals in the host country. Hence while we are not estimating a gravity model of migration we conjecture that including exposure to compulsory foreign language courses into a traditional gravity model could improve its explanatory power. ${ }^{8}$ To the extent that cultural proximity to certain countries makes it more likely that their languages are studied during compulsory education, this chapter also proposes an additional micro-channel explanation for the finding that cultural distance matters for migration decisions. ${ }^{9}$ To the best of our knowledge we are the first to analyze how foreign language proficiency acquired during compulsory education determines migration.

The remainder of this chapter is organized as follows. The next section describes our estimation strategy. In Section 3 we present our data. Section 4 presents and discusses our results, and Section 5 concludes.

\section{Estimation Strategy}

We estimate the following model:

$$
\begin{aligned}
M_{a, o, d, t}= & \beta_{0}+\beta_{1} L_{a, o, d, t}+\beta_{2} D_{a}+\beta_{3} D_{o}+\beta_{4} D_{d}+\beta_{5} D_{t}+\beta_{6} D_{a, o}+\beta_{7} D_{a, d}+ \\
& +\beta_{8} D_{a, t}+\beta_{9} D_{o, d}+\beta_{10} D_{o, t}+\beta_{11} D_{d, t}+\beta_{12} X_{t-1}+\epsilon_{a, o, d, t}
\end{aligned}
$$

where $M$ is the number of immigrants of age $a$ from country $o$ going to country $d$ in year $t$. $L$ denotes exposure to compulsory language courses in the official language of country $d$, and $D_{s}$ with $s=a, o, d, t$ are dummies for age, country of origin, destination country, and year. Our main specification of the model includes all four dummy variables and their simple interactions. In addition we also specify a model that includes certain

\footnotetext{
${ }^{8}$ Fidrmuc and Fidrmuc [2013] present a gravity model that includes measures of foreign language proficiency. However, the authors do not consider migration but apply the model to study intra-European trade instead.

${ }^{9}$ Our framework also picks up migration decisions by minority groups, whenever the presence of those groups has had an impact on the national school curriculum. For instance, Swedish is taught at Finish schools and thus we account for Swedish-speakers in Finland who migrate to Sweden.
} 
triple interactions of dummy variables. For instance, we add the interaction term $D_{d, o, t}$ between destination country, country of origin, and year. This term accounts for pull and push factors between countries that change over time and that are common to all cohorts of immigrants from the same country of origin. Including these dummy variables is equivalent to including control variables from typical gravity models like differences in the share of young individuals in the labor force, female labor force participation rates, or average wage differentials. We also include the interaction term $D_{d, a, t}$ between destination country, age group, and year to take into account any age-specific changes in the labor demand of the destination country. Moreover, to control for network effects and economic factors we include as control variables $\left(X_{t-1}\right)$ the stock of immigrants by country of origin and the difference in the unemployment rates between the destination country and the country of origin, both in $t-1$ and by age group.

Given that only some languages are studied as foreign languages during compulsory education in European schools, the maximum set of foreign languages considered is composed of English, German, French, Spanish, and Italian. ${ }^{10}$ While for most countries, second foreign languages are either German or French, for individuals in Portugal, Greece, France, and Italy we also include Spanish and for individuals in Malta, Italian. For each country we specifically include all possible choices of languages. This guarantees that individual choices which are potentially correlated with migration intentions and differences in labor market conditions of origin and destination countries do not alter the estimated effect. For destination countries where neither English, German, French, Spanish, or Italian are official languages, we set $L_{a, o, d, t}=0$ for all $t, a, o$. For migration between countries that share the same national language, as Germany and Austria, UK and Ireland, France and Belgium, or the Netherlands and Belgium we set $L_{a, o, d, t}=1$ for all $t, a$. As a result, in our model specification that includes triple interactions some variables $D_{d, o, t}$ and $D_{d, a, t}$ are not going to be identified. However, as long as identifying these dummy variables is not the focus of our analysis this will not pose a mayor problem for our estimation. Following Bertrand et al [2004] we cluster standard errors at the destination-origin-age level to allow for serial correlation in migration flows over time.

Our analysis compares migration decisions of individuals from different groups within countries as well as across countries In particular, we test whether younger individuals who were exposed to compulsory foreign language courses make different migration decisions than older cohorts who were not affected by educational reforms. In addition, we

\footnotetext{
${ }^{10}$ Even though Russian is the most widely taught second foreign language in Latvia, Estonia, and Lithuania we ignore this option given that migration to Russia is restricted, different from migration within the EU.
} 
also test for differences across countries, namely whether individuals in countries with foreign language learning during compulsory education are more likely to migrate to a country where the target language is spoken. Technically, our estimation strategy could be described as a multidimensional difference in difference (DiD) approach. The traditional DiD approach compares the evolution of a treated unit to the evolution of an untreated unit to capture the effect of the treatment. However, we depart from the traditional DiD approach and extend it in two ways: (i) we make use of more than two dimensions and (ii) we include more than one treated group, each group with different treatments. Conclusions derived from a traditional DiD estimation could be misleading because within such a restricted framework we could only compare two countries: (i) country $\mathrm{T}$ where a younger cohort $\mathrm{K}+1$ studied the language of country $\mathrm{L}$ but where an older cohort $\mathrm{K}$ did not study it and (ii) country $\mathrm{C}$ where none of the two cohorts studied the language of country L. If we only took first differences we would observe cohort-specific migration rates from country $\mathrm{T}$ to country $\mathrm{L}$. We would thus attribute any differences in migration rates between the two cohorts to the educational reforms occurred in country T. However, there are other reasons why cohorts differ in their propensities to migrate. Hence, in order to disentangle the effect of language skills on migration from generational propensities to migrate we could also consider differences in migration rates between the two cohorts in country C. Then, using differences in (cohort) differences in migration rates in countries $\mathrm{T}$ and $\mathrm{C}$, we would obtain an estimate of the impact of language skills on migration which is not affected by generational factors.

However, this traditional DiD method is only valid under the assumption that generational factors affect migration similarly in countries $\mathrm{C}$ and $\mathrm{T}$. Again this assumption might be too restrictive. In order to increase the reliability of our estimation we include destination country and year as additional dimensions. Controlling for the country of destination allow us to compare migration decisions of individuals from two different countries where different foreign languages are studied. Including year of migration, on the other hand, allow us to capture additional push and pull factors of migration that change over time. Hence, we also exploit the fact that language instruction reforms happen at different times, and thus affect different cohorts and languages. In our estimation, we thus deal with a large number of exposed and non-exposed groups of individuals, because we take into account the educational policy changes that affected foreign language learning in compulsory education over the last decades in those EU countries for which data is available. 


\section{Data}

We use Eurostat's database on migration among EU countries. In particular we look at the flow and stock of immigrants in $t-1$ by 5 -year age groups in destination countries in 2008, 2009, and 2010. Destination countries that provide this data are the following 24 countries: Austria, Belgium, Croatia, Cyprus, Czech Republic, Denmark, Estonia, Finland, Germany, Hungary, Ireland, Italy, Latvia, Liechtenstein, Lithuania, Luxembourg, Macedonia, Netherlands, Norway, Poland, Slovakia, Slovenia, Spain, and Sweden. For Germany and Austria, data for 2009 and 2010 is missing and we complement it with data from the Statistisches Bundesamt [2013] and Statistik Austria [2013], respectively. Data for the UK come from the International Passenger Survey provided by the UK Office for National Statistics, ONS [2013]. Note that data for migration flows to France, Greece, Malta, and Portugal is not available. Hence, we have information on 25 destination countries and 29 countries of origin - all destination countries plus France, Greece, Malta, and Portugal. Eurostat also provides information on unemployment rates by age groups. For our analysis we only consider individuals between 25 and 44 . To avoid picking up temporary migration related to studying abroad, we restrict our sample to individuals of working age ( $>25$ years). In many countries, for individuals older than 44, i.e. those born before 1964, it is unclear that language learning (or even compulsory schooling) was enforced.

Our data on exposure to foreign languages in compulsory education come from the European Commission's Education, Audiovisual and Culture Executive Agency (EACEA) [2012]. We use data from the European's Commission's Directorate-General for Education and Culture [2001] to construct a database including information on the starting age for studying foreign languages during compulsory education. Educational reforms that have occurred during the last decades imply that individuals of different cohorts may have been exposed or not to foreign languages during compulsory education. There are also differences in the choice of foreign languages studied over time. For instance, in Spain French used to be the first foreign language studied during secondary education. Three decades ago however, students began studying English as the first foreign language. In former communist countries of Central and Eastern Europe, Russian has been replaced by English as the first foreign language. These changes generate within- and across-country variation in the exposure to foreign languages. Our data set contains this information by age group and country of origin.

Our age restriction implies that individuals in all countries - with the exception of Belgium and some Central and Eastern European countries (Croatia, Czech Republic, Estonia, 
Hungary, Latvia, Macedonia, Slovakia, and Slovenia) - were exposed to English as a first foreign language. In Central and Eastern Europe the change from Russian to English as the first foreign language was clearly driven by the end of communism, which in itself had important implications for migration flows. Given that we consider migration in years 2008-2010, most of the initial emigration boom is likely to have ebbed out. Even if that were not the case, in our estimation we compare migration decisions of individuals who were and those who were not exposed to English as a foreign language. If the end of communism were still the main driving force for migration in 2008-2010, then - controlling for differences in age - we should not observe any marked differences in migration decisions between the two groups. For instance, comparing two individuals from the same ex-communist country, one born in 1980 and another one born in 1977, the former was exposed to English as a foreign language while the latter was not. If both individuals migrated to the UK or Ireland origin-destination-fixed effects would capture their decision, and it would not contribute to our estimated effect of language proficiency on migration. Only in case the younger, but not the older, individual migrated to the UK or Ireland would we attribute his migration decision to the newly acquired English skills.

As mentioned before, exposure to compulsory second foreign language differs across countries. The most widely taught second foreign languages in Europe are French, German, and Spanish. Italian is taught in fewer countries. We also take into account that there are countries where studying a second foreign language is not part of compulsory education, and that students in Finland learn Swedish as a foreign language.

Table 3.1 provides summary statistics - mean, standard deviation and minimum and maximum values - for our variables. We have observations for 6,784 combinations of origin*destination*age* year. ${ }^{11}$ Around 148 individuals in each age group from each country of origin migrate each year to one of the destination countries. However, there is large variation. Individuals from some age groups and countries of origin do not migrate to certain countries. On the other hand, the inflow of individuals from some age groups and countries of origin is 100 times more common compared to the mean. In particular, 19,000 Polish immigrants of age 25-29 entered the UK in 2010. Around 8-9\% of our observations - cells defined by the combination of origin, destination, age, and year - are treated, i.e. exposed to the language of the destination country during compulsory education. We have slightly more observations for 2008 than for 2009 or 2010. Regarding differences in unemployment rates by age groups we observe the maximum difference of almost 40

\footnotetext{
${ }^{11}$ In total we should have 8,700 observations. Unfortunately, we were not able to complement the following missing data for destination countries: for 2009 and 2010 for Croatia, Cyprus, Macedonia, Poland; for 2008 and 2010 for Belgium; for 2010 for the Netherlands. The remaining missing data refers to single observations; for instance for half of all countries migration from Liechtenstein is missing.
} 
Table 3.1: Summary statistics

\begin{tabular}{lcccc}
\hline \hline \multicolumn{1}{c}{ Variable } & Mean & Std. Dev. & Min. & Max. \\
\hline imm flow origin-destination by age group & 148.098 & 591.050 & 0 & 19000 \\
treated & 0.086 & 0.278 & 0 & 1 \\
age group 25-29 & 0.252 & 0.434 & 0 & 1 \\
age group 30-34 & 0.252 & 0.434 & 0 & 1 \\
age group 35-39 & 0.248 & 0.432 & 0 & 1 \\
age group 40-44 & 0.248 & 0.432 & 0 & 1 \\
year: 2008 & 0.382 & 0.486 & 0 & 1 \\
year: 2009 & 0.317 & 0.465 & 0 & 1 \\
year: 2010.0000 & 0.301 & 0.459 & 0 & 1 \\
diff. unemploy. origin -destination by age, & 1.112 & 5.742 & -38.7 & 29.8 \\
stock imm origin-destination by age, & 508.466 & 2447.845 & 0 & 41744 \\
\hline \hline
\end{tabular}

$\mathrm{N}=6784$; Differences in unemployment rates and the stock of immigrants refer to years $t-1$, i.e 2007, 2008, 2009. Sources: Eurostat, Statistisches Bundesamt [2013], Statistik Austria [2013], ONS [2013], European Commission's Education, Audiovisual and Culture Executive Agency (EACEA) [2012], European's Commission's Directorate-General for Education and Culture [2001]; own calculations

percentage points between unemployment rates in the Netherlands and Macedonia for individuals aged 25-29 in 2008. Measured one year before migration, the average number of immigrants of a certain age group and from a certain country of origin is around 500, i.e. more than three times the average annual inflow. In some countries there are no immigrants of a specific age group from a certain EU country, while there are 41,744 immigrants from France age 40-44 in Spain.

\section{Results}

As mentioned before for the case of Spain, over the last decades English has replaced French as the first foreign language in a variety of countries. In fact, before 1973 when Britain joined the EU, French used to be the most commonly used working language in the EU, see Gazzola [2006]. Today English is clearly the EU's dominant tongue, see Phillipson [2003]. Thus, younger cohorts of individuals are more likely to have learned English as a foreign language during compulsory education, and they are more likely to migrate to English speaking countries. Older cohorts on the other hand, learned French and would prefer to migrate to French speaking countries. Table 4.2 provides statistics on the ratio of young $(<34)$ to old $(>35)$ EU immigrants in different countries. We observe 
a high ratio of young to old immigrants, in particular in the UK but also in Ireland. This ratio is lower in Belgium. While this age composition might also be driven by other migration motives, we conjecture that part of these observed differences might be driven by differences in language proficiency of distinct cohorts.

Table 4.2: Ratio of "young" to "old" EU immigrants, 2010

\begin{tabular}{l|l|l} 
Country of Destination & Number of Immigrants & young $(<34) /$ old $(>35)$ \\
\hline \hline Austria & 26,809 & 1.676 \\
Belgium & 25,086 & 1.69 \\
Czech Republic & 7,960 & 2.109 \\
Denmark & 6,907 & 2.812 \\
Estonia & 210 & 1.188 \\
Finland & 3,596 & 1.801 \\
Germany & 99,083 & 1.55 \\
Ireland & 7,335 & 3.376 \\
Italy & 12,094 & 1.724 \\
Latvia & 368 & 1.629 \\
Liechtenstein & 131 & 1.339 \\
Lithuania & 56 & 1.333 \\
Luxembourg & 6,311 & 1.61 \\
Norway & 19,906 & 2.192 \\
Slovakia & 2,860 & 1.226 \\
Slovenia & 1,548 & 1.183 \\
Spain & 31,537 & 1.705 \\
Sweden & 11,825 & 2.041 \\
United Kingdom & 59,000 & 5.556 \\
\hline \hline
\end{tabular}

Eurostat [2012d]; own calculations

Table 4.3 contains the estimation results of our model that considers exposure to a foreign language during compulsory education as an instrument for language proficiency. In particular, we consider how having been exposed to English, French, and German during compulsory education raises the odds of migrating to the UK, Ireland, Belgium, Germany, or Austria. For individuals in Portugal, Greece, France, and Italy we also consider if having been exposed to Spanish increase the odds of migrating to Spain. Finally, for individuals in Malta we consider if having been exposed to Italian increase the odds of migrating to Italy. Our results show that this is clearly the case. The coefficient of interest remains stable even after controlling for destination country, country of origin, age 
group, and year effects as well as all their first order interactions and some second order interactions. We find that speaking the language of a host country increases migration to that country almost fivefold. Exposure to language learning during compulsory education increases the number of individuals of a cohort that migrate to the country where the language is spoken by 544 per year, a magnitude similar to the standard deviation of the number of immigrants in the sample.

Table 4.3: Results

\begin{tabular}{lcccc} 
& $(1)$ & $(2)$ & $(3)$ & $(4)$ \\
\hline treated & 813.91 & 521.079 & 523.899 & 544.316 \\
& $(339.438)^{* *}$ & $(236.434)^{* *}$ & $(260.825)^{* *}$ & $(273.013)^{* *}$ \\
Destination by age & & $\mathrm{X}$ & $\mathrm{X}$ & $\mathrm{X}$ \\
Destination by year & & $\mathrm{X}$ & $\mathrm{X}$ & $\mathrm{X}$ \\
Origin by year & & $\mathrm{X}$ & $\mathrm{X}$ & $\mathrm{X}$ \\
Origin by age & $\mathrm{X}$ & $\mathrm{X}$ & $\mathrm{X}$ \\
Destination by origin by year & & & $\mathrm{X}$ & $\mathrm{X}$ \\
Destination by age by year & & & & $\mathrm{X}$ \\
Obs. & 6784 & 6784 & 6784 & 6784 \\
$R^{2}$ & 0.762 & 0.843 & 0.868 & 0.872 \\
\hline \hline
\end{tabular}

The dependent variable is the number of immigrants, the variable treated identifies the cohorts from the country of origin who were exposed to learning the language of the country of destination during compulsory schooling. The coefficients are marked with * if the level of significance is between $5 \%$ and $10 \%,{ }^{* *}$ if the level of significance is between $1 \%$ and $5 \%$ and $* * *$ if the level of significance is less than 1\%. All regressions contain year-fixed effects, age indicators, binary variables for each pair of origin and destination countries, dummies for each combination of age and year, a variable for differences in lagged unemployment rate between origin and destination countries and the stock of co-nationals from each cohort in the destination country in the previous period. Errors are clustered by origin-destination-age.

However, educational reforms related to foreign language learning might be endogenous to migration if differences in unemployment rates between origin and destination countries jointly determine reforms and migration patterns. Governments might decide to start teaching a foreign language trying to encourage migration to certain countries with lower unemployment rates where the foreign languages in question are spoken. For instance, given the current economic situation in their countries of origin, migration by Portuguese, Spanish, and Greek citizens to Germany has increased over the last years (see Figure A-3 of the Appendix A). If this increase in migration led governments to strengthen teaching of German at compulsory levels, we would observe a further rise in migration that would ultimately be caused by the differences in unemployment rates rather than by the improved language skills. 
The OECD [2013] provides series of unemployment rates from 1956 onwards. We consider differences in unemployment rates between countries that implemented reforms in foreign language teaching and countries where these languages are spoken. Table 4.4 provides average differences in unemployment rate five years prior to reforms and ten years before and after the reform. Negative differences indicate that unemployment in the country carrying out the educational reform was lower than in the country where the foreign language is spoken. In these cases we can completely disregard the concern that reforms might be driven by governments desire to encourage migration to these countries. In general, we do not observe any clear relation between educational reforms and unemployment rates. Governments' educational reforms regarding foreign languages in compulsory education do not seem to react to unemployment. On the contrary, most reforms seem to have taken place in periods of low relative unemployment.

Table 4.4: Relationship: Language Learning and Differences in Unemployment Rates

\begin{tabular}{l||l|l|l|l|l|l|l|} 
& Belgium & Denmark* & France & Italy & Portugal & Sweden & Greece \\
\hline Year Reform $(\mathrm{t})$ & 1971 & 1961 & 1985 & 1995 & 1990 & 1982 & 1981 \\
\hline Differences U-Rates: & & & & & & & \\
with Germany $t+10 / t-10$ & 1.98 & 0.93 & 1.87 & 2.84 & -0.65 & -6.03 & 0.19 \\
with Germany $t-6 / t-1$ & 1.32 & 1.67 & 1.41 & 4.18 & 0.62 & -1.40 & -1.60 \\
with Austria $t+10 / t-10$ & 2.11 & 0.03 & 4.63 & 6.86 & 2.82 & -0.02 & 2.19 \\
with Austria $t-6 / t-1$ & 0.58 & 0.96 & 4.17 & 7.26 & 3.60 & 0.31 & 0.13 \\
with France $t+10 / t-10$ & - & 0.73 & - & 1.56 & -2.57 & -3.94 & -1.47 \\
with France $t-6 / t-1$ & - & 3.04 & - & 1.80 & -2.32 & -3.14 & -2.93 \\
with Belgium $t+10 / t-10$ & - & -0.17 & - & 0.49 & -4.72 & -6.03 & -3.52 \\
with Belgium $t-6 / t-1$ & - & 0.96 & - & 0.08 & -4.17 & -5.74 & -5.19 \\
with Spain $t+10 / t-10$ & - & - & -8.04 & -6.69 & -12.24 & - & -7.29 \\
with Spain $t-6 / t-1$ & - & - & -8.54 & -8.73 & -12.91 & - & -5.40 \\
\hline \hline
\end{tabular}

Data: OECD [2013]; for Denmark average differences in unemployment 5 years before and 10 years after reform; negative differences indicate higher unemployment rates in Germany, Austria, France, Belgium, Spain.

Maybe differences in unemployment rates do not capture well enough differences in countries' economic situations that make individuals migrate from their host country to a certain destination country. In that case there could still exist some concern that foreign language teaching and migration be related both ways, with governments reforming foreign language curricula in order to facilitate their citizen's emigration to other coun- 
tries. However, educational reforms take at least 5-15 years to show any effect while most governments' mandates are restricted to 4 years, making this strategy rather unlikely. In addition, we argue that introducing or strengthening teaching of foreign languages requires increased government spending. Hence, such policies are rather unlikely to be implemented in situations of economic crisis and fiscal austerity, but are more likely to happen in times of budget surpluses. Similar to a luxury good, spending on foreign language teaching is likely to increase with sound public finances rather than with migration outflows.

To the best of our knowledge there does not exist any established theory on the political economy of reforming foreign language curricula. This is why we consider various historical reforms to check for any evidence of reversed causality. When looking at reforms in Japan related to English as a foreign language, most arguments concern the need for communication with the rest of the world. There are also examples of reforms that are related to pedagogical concerns rather than economic ones. For instance, a recent reform in Japan that reduced hours of - among other subjects - foreign languages intended to provide students with more flexibility for their curricula, see Butler and Iino [2005]. The historical motive for foreign language teaching (English) in China, after the end of the Mao era, and as stated by Deng Xiaoping, was to enable citizens to acquire the latest know-how related to scientific and technical knowledge, see $\mathrm{Hu}$ [2005]. If this knowledge is acquired by studying abroad, then indeed foreign language teaching will foster migration. However, many scholarship programs that explicitly include return clauses, and different returnee programs seem to indicate that in general, governments are not interested in permanent migration of their citizens. In England and Wales, from September 2014 onwards, foreign language learning will become compulsory for students age 7-14, see Department for Education [2013]. All maintained schools will have to offer one of the following foreign languages: French, German, Italian, Mandarin, Spanish, Latin, or Ancient Greek. For the last two languages we can clearly dismiss any concern about reversed causality. Furthermore, there is no predetermined choice for one particular foreign language by the government. The list of languages was elaborated based on responses by stakeholder (education authorities, parents etc.) regarding most popular foreign languages. Responses by stakeholder furthermore revealed the following arguments in favor of learning a foreign language: (1) greater understanding and tolerance of other people, cultures and societies, and broadening of minds to an increasingly international environment, (2) to support the development of literacy skills in English and to enhance problem solving skills demanded by other areas of the curriculum, (3) beneficial to the global economic competitiveness and for filling the country's skill gap in this area.

Governments' motivations for reforming foreign language teaching stem from a need to 
improve their citizens' overall human capital. Foreign language proficiency is crucial for working in a globalized world and in particular in sectors such as tourism or trade, science, international relations, or media. There are no indications that in times of high unemployment governments respond to increased migration to a certain country by improving its citizens' language skills of that particular country. On the contrary, to guarantee the sustainability of the pension system, governments need a large and highly qualified working population. Fostering emigration to reduce the negative effect of unemployment benefits on the social security system, seems rather short-sided in comparison. Furthermore, common to all reforms mentioned, they are part of larger educational reforms affecting other subjects (e.g maths, history, etc.). It is unlikely that the timing of educational reforms is driven by aspects of foreign language learning only. Moreover, many educational reforms are clearly linked to changes in governing parties, and some are motivated by ideological differences between parties, with the public debate oftentimes focusing on subjects such as religion or history.

\section{Conclusion}

There are huge differences in youth unemployment rates across Europe. Migration does not seem to react sufficiently to these differences. Comparing European and US migration rates suggests that differences in languages across European countries might be important for explaining why European labor is relatively immobile. In addition, results from gravity models for migration suggest an important influence of language and linguistic distance on migration. However, linguistic distance is typically considered a static characteristic. Learning a foreign language is a way to overcome this distance. Language skill acquisition thus adds a dynamic dimension to linguistic distance. In this chapter we provide an analysis of the impact of foreign language learning during compulsory education on migration flows across Europe. In line with previous literature, our results suggest a positive impact of common language on migration probabilities. In particular, we find that speaking the language of a country increases the likelihood to migrate to that country almost fivefold.

Moreover, in its dynamic version linguistic distance becomes a policy variable. By changing the curricula of foreign language learning during compulsory education governments can determine their citizens' foreign language proficiency and ultimately influence their migration decisions. In this sense, governments may be taking into account already existing trends in migration or differences between countries' labor markets when designing foreign language curricula for compulsory education. However, we check this last point and find no evidence for such a relationship. 
We consider this analysis a starting point for a broader study of other factors that could help to explain the link between language proficiency and migration. For instance, within our framework we have not considered the difficulty of acquiring a certain foreign language. While we conjecture that the magnitude of our estimated result is likely to differ by linguistic distance between acquired language and mother tongue, adding this aspect to our framework suggests an interesting road for future research. Furthermore, for some highly qualified employees the language of the workplace is English, independently of their country of residence. Within our suggested framework, it could be interesting to analyze, whether proficient English speakers choose to migrate to countries where their skills are less common, but highly demanded; for instance if individuals from English speaking countries tend to migrate to countries with few proficient English speakers, as for instance China, see Economist [2006].

\section{References}

Adsera, Alicia and Mariola Pytlikova (2012): "The Role of Language in Shaping International Migration,"IZA Discussion Paper No. 6333.

Belot, Michèle and Sjef Ederveen (2012): "Cultural barriers in migration between OECD countries," Journal of Population Economics, 25, pp.1077-1105.

Bertoli, Simone; Fernández-Huertas Moraga, Jesús and Francesc Ortega (2013): "Crossing the border: Self-selection, earnings and individual migration decisions," Journal of Development Economics, 101, pp.75-91.

Bertrand, Marianne, Esther Duflo and Sendhil Mullainathan (2004): "How much should we trust differences-in-differences estimates?," Quarterly Journal of Economics, 119(1), pp.249-275.

Bleakley, Hoyt and Aimee Chin (2010): "Age at Arrival, English Proficiency, and Social Assimilation among US Immigrants," American Economic Journal: Applied Economics, 2(1), pp.165-192.

Bureau of Labor Statistics (2012): States: Employment status of the civilian noninstitutional population by sex, race, Hispanic or Latino ethnicity, marital status and detailed age, 2011, annual averages. 
Butler, Yuko Goto and Masakazu Iino (2005): "Current Japanese Reforms in English Language Education: The 2003 "Action Plan", Language Policy, 4, pp.25-45.

Chaloff, Jonathan and Georges Lemaître (2009): "Managing Highly-Skilled Labour Migration. A Comparative Analysis of Migration Policies and Challenges in OECD Countries," OECD Social, Employment and Migration Working Papers No. 79 .

Chiswick, Barry R. (2008): "The Economics of Language: An Introduction and Overview," IZA DP No. 3568.

Chiswick, Barry R. and Paul W. Miller (2001): "Model of DestinationLanguage Acquisition: Application to Male Immigrants in Canada," Demography, 38(3), pp.391-409.

Chiswick, Barry R. and Paul W. Miller (2010): "Occupational Language Requirements and the Value of English in the US Labor Market," Journal of Population Economics, 23(1), pp.353-372.

Department for Education (2013): Consultation Report. Foreign languages at Key Stage 2, February 2013.

Dustmann, Christian, and Francesca Fabbri (2003): "Language Proficiency and Labour Market Performance of Immigrants in the UK," Economic Journal, 113, pp.695-717.

Economist, The (2006): The language business in China. English beginning to be spoken here, April 12th, print edition.

European Commission (2012): Employment, Social Affairs and Inclusion.

European Commission, ESLC (2012): First European Survey on Language Competences, Final Report.

European Commission's Education, Audiovisual and Culture Executive Agency, EACEA (2012): Key Data on Teaching Languages at School in Europe.

European Commission's Directorate-General for Education and Culture (2001): Foreign Language Teaching in Schools in Europe. Country Reports.

Eurobarometer (2012): "Europeans and their Languages," Special Eurobarometer 386, Directorate General for Education and Culture, European Commission.

Eurostat (2012a): Unemployment rate, annual average, by sex and age groups. 
Eurostat (2012b): Average number of foreign languages learnt per pupil at ISCED level 2 and 3 .

Eurostat (2012c): Pupils learning English, French, German at upper secondary education.

Eurostat (2012d): Statistics: Population and social conditions.

Eurostat (2013): Statistics: Population by age group and citizenship.

Farré, Lidia; González, Libertad and Francesc Ortega (2010): "Immigration, Family Responsibilities and the Labor Supply of Skilled Native Women," B.E. Journal of Economic Analysis 83 Policy, 11(1), pp.1-48.

Fidrmuc, Jan and Jarko Fidrmuc (2013): "Foreign Languages and Trade," Brunel University, Working Paper 09-14.

Furtado, Delia and Heinrich Hock (2010): "Low Skilled Immigration and WorkFertility Tradeoffs Among High Skilled US Natives," American Economic Review, Papers \& Proceedings, 100, pp. 224-228.

Gazzola, Michele (2006): "Managing Multilingualism in the European Union: Language Policy Evaluation for the European Parliament," Language Policy, 5, pp. 393417.

Hofstede, Geert; Hofstede, Gert Jan and Michael Minkov (2010): textit Cultures and Organizations: Software of the Mind, McGraw-Hill USA, 2010

Hu, Guangwei (2005): "English Language Education in China: Policies, Progress and Problems," Language Policy, 4, pp.5-24.

Inglehart, Roland and Wayne E. Baker (2000): "Modernization, Cultural Change, the persistence of traditional value," American Sociological Review, 65(1), pp.19-51.

Kennan, John and James R. Walker (2011): "The effect of expected income on individual migration decisions," Econometrica, 79(1), pp. 211-251

Lewer, Joshua and Hendrik Van den Berg (2008): "A Gravity Model of Immigration," Economics Letters, 99 (1), pp.64-167.

Molloy, Raven; Smith L. Christopher and Abigail Wozniak (2011): "Internal Migration in the United States," Finance and Economics Discussion Series Divisions of Research \& Statistics and Monetary Affairs, Federal Reserve Board, Washington, D.C. 
OECD (2013): Annual labor force statistics, Organisation for Economic Cooperation and Development, Paris.

OECD (2012a): International Migration Outlook 2012, Organisation for Economic Co-operation and Development, Paris.

OECD (2012b): Economic Surveys: European Union, Annual cross-border mobility: Per cent of total population 2010, Organisation for Economic Co-operation and Development, Paris.

ONS (2013): UK Inflow from Individual EU Countries of birth by five year age groups and sex for years 2008, 2009, 2010. Estimates from the International Passenger Survey, Published ad hoc data and analysis: Population, requests during April 2013.

Ortega, Francesc and Giovanni Peri (2009): "The Causes and Effects of International Migrations: Evidence from OECD Countries 1980-2005," NBER Working Paper No. 14833.

Phillipson, Robert (2003): English-Only Europe? Challenging Language Policy, Routledge, New York, 2003.

Schildkraut, Deborah J. (2001): "Official-English and the States: Influences on Declaring English the Official Language in the United States," Political Research Quarterly, 54 (2), pp.445-457.

Statistisches Bundesamt (2013): "Sonderauswertung des Ausländerzentralregisters 2008, 2009 und 2010, Zugänge in das Ausländerzentralregister in den genannten Jahren nach Staatsangehörigkeiten und 5er-Altersgruppen", by petition.

Statistik Austria (2013): "Sonderauswertung der Wanderungsstatistik 2008, 2009 und 2010 nach ausgewählter Staatsangehöhrigkeit und 5er-Altersgruppen", by petition.

US Census Bureau (2013): "Language Use in the United States: 2011; American Community Service"

Winters, Paul de Janvry, Alain and Elisabeth Sadoulet (2001): "Family and Community Networks in Mexico-U.S. Migration," Journal of Human Resources, 36(1), pp.159-184. 


\section{A Appendix}

Figure A-1: Share of EU-27 foreigners among total population by country

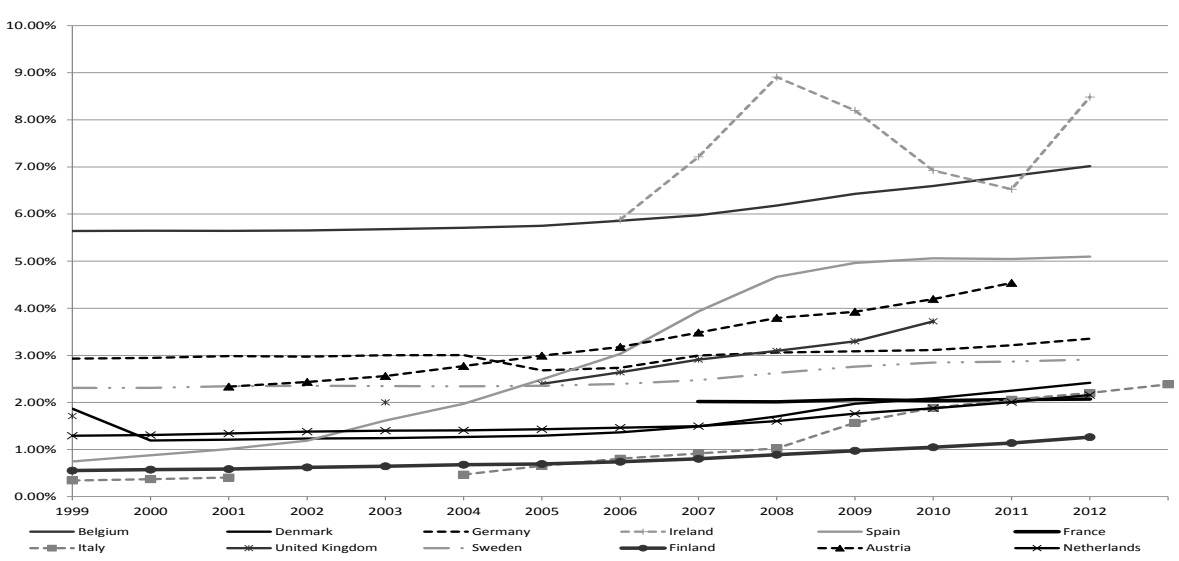

Data: Eurostat [2013], own calculations.

Figure A-2: Share of young EU-27 foreigners among total young (20-29 years)

population by country

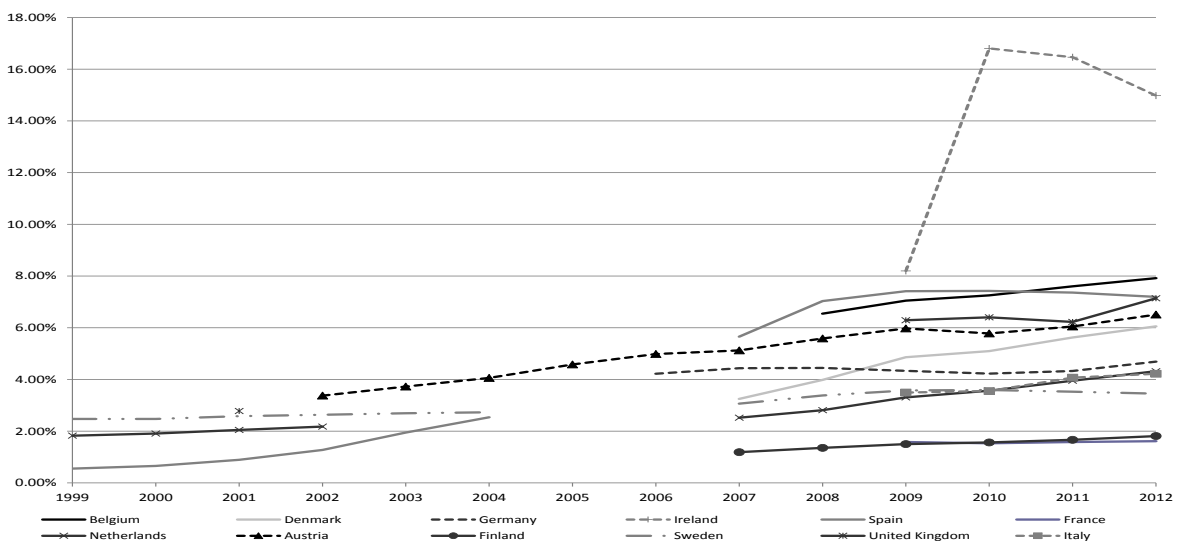

Data: Eurostat [2013], own calculations. 
Figure A-3: Recent migration from Greece, Ireland, Portugal and Spain to Germany

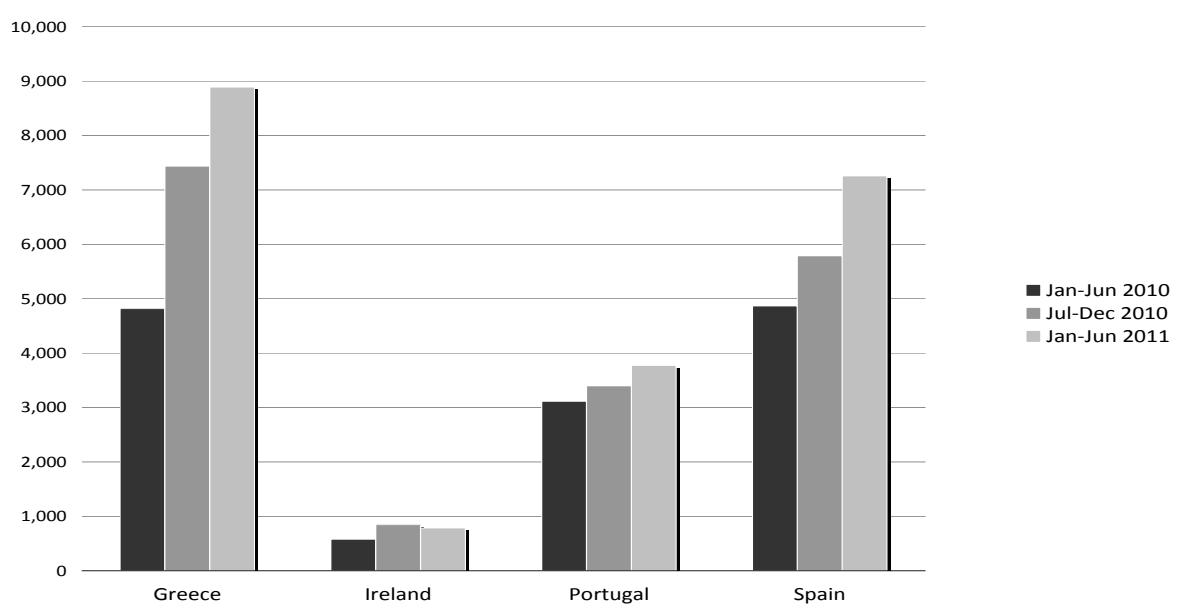

Data: OECD [2012a]

Figure A-4: Percentage of Students learning foreign languages in selected EU countries

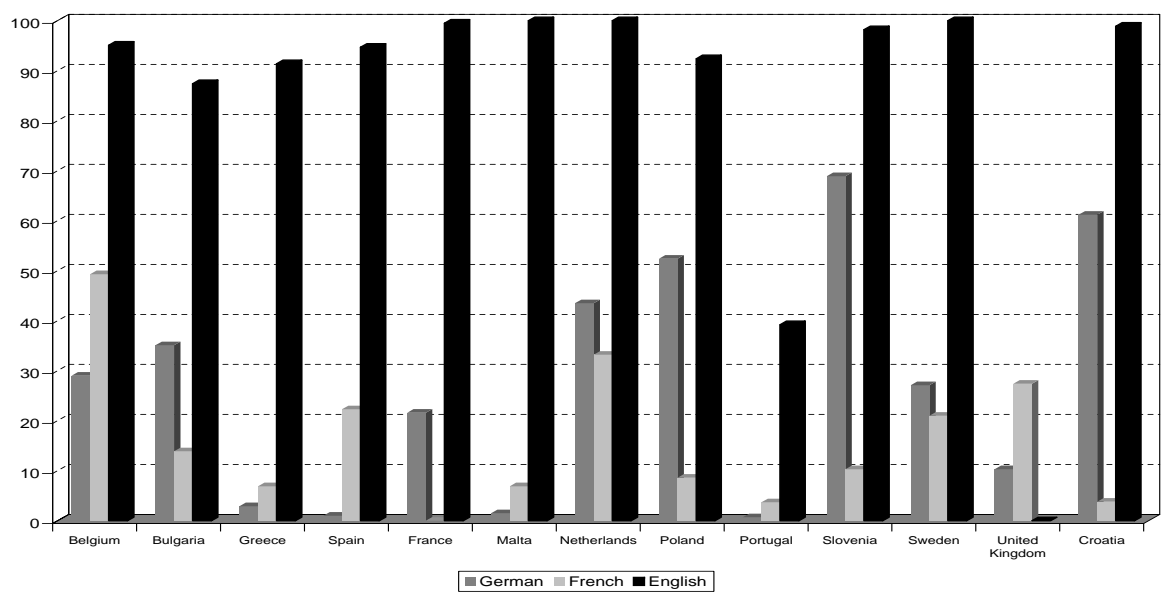

Data: Eurostat [2012c] 